\title{
An ABC Optimized Adaptive Fuzzy Sliding Mode Control Strategy for Full Vehicle Active Suspension System
}

\author{
Atheel K. Abdul Zahra*, Turki Y. Abdalla \\ Computer Engineering Department, University of Basrah, Basrah, Iraq
}

Correspondence

*Atheel K. Abdul Zahra

Computer Engineering Department,

University of Basrah, Basrah, Iraq

Email: atheel.abdulzahraa@uobasrah.edu.iq

\begin{abstract}
This work presents a Fuzzy based adaptive Sliding Mode Control scheme to deal with control problem of full vehicle active suspension system and take into consideration the nonlinearities of the spring and damper, unmodeled dynamics as well as the external disturbances. The control law of fuzzy based adaptive Sliding Mode Control scheme will update the parameters of fuzzy sliding mode control by using the stability analysis of Lyapunov criteria such that the convergence in finite time and the stability of the closed loop are ensured. The proposed control scheme consists of four similar subsystems used for the four sides of the vehicle. The sub control scheme contains two loops, the outer loop is built using sliding mode controller with fuzzy estimator to approximate and estimate the unknown parameters in the system. In the inner loop, a controller of type Fractional Order PID (FOPID) is utilized to create the required actuator force. All parameters in the four sub control schemes are optimized utilizing Artificial Bee Colony $(A B C)$ algorithm in order to improve the performance. The results indicate the effectiveness and good achievement of the proposed controller in providing the best ability to limit the vibration with good robustness properties in comparison with passive suspension system and using sliding mode control method. The controlled suspension system shows excellent results when it was tested with and without typical breaking and bending torques.

KEYWORDS: ABC Technique Algorithm, Active Suspension System, FOPID Controller, Fuzzy Estimator, Sliding Mode Control.
\end{abstract}

\section{INTRODUCTION}

Suspension systems are vital elements of any vehicle, which contain all the structures of transmission between the body of vehicle and its wheels. Furthermore, suspension systems are essential to all automobiles to achieve comfortable driving and better dealing with road against the disturbances and irregularities of the road by buffering the different vibration forms that resulted of uneven road and then transfer the braking and driving forces to improve the comfortable driving and the stability of driving vehicle [1][3].

Suspension systems can be classified into passive, semiactive and active suspension system and any one of these three types of suspension system has been made up of the dampers, springs, as well as the connecting structures. The passive suspensions system possesses fixed damping rates and cannot adapt to varied road conditions and there is no energy provided by the suspension components to the system, but they control the motion of the vehicle body to the tire by employing different kinds of damping or energy wasted elements. The performance of passive system cannot be improved. Semi - active suspension systems involve variable damping characteristics, consume low power and do not need expensive power supply but they give a considerable improvement. This form of suspension system utilized external energy to operate. Actuator and sensors are added to discover the road profile and disturbance for control input. To overcome the limitations of passive and semi active suspensions, active suspension systems are used. The active suspension system has electromagnetic or hydraulic actuators commonly situated in parallel with damper and spring which dissipate energy from the system [4], sensors 
which measure suspension variables, and control unit that can enter the desired force and can be controlled via different kinds of controllers. The active suspension possesses the capability to response to the various changes of the disturbances and road inputs and can achieve tradeoff between comfortable driving, the deflection of suspension and tire, so, active suspension system is used since it is more efficient than other types.

\section{LITERATURE REVIEW}

Today, practical environment, growing performances of control in the presence of different uncertainties that has been related with the external disturbance and model errors is an important matter in different fields, such that it can affect the control of vibration in the suspension systems of vehicle and the accurate control of tracking different other systems. To develop many advanced schemes of control that can deal with this matter, various researchers presented different control strategies to improve active suspension system goodness and handle stability requirements at the last three decades involving Sliding Mode Control (SMC) methods [5, 6], Fuzzy Logics (FL) [7, 8], and hybrid control techniques $[9,10]$. The typical benefits of (SMC) include the robustness versus uncertainties, simple implementation in addition to the possibility to overcome and deal with the applied disturbances. Also, it can be simply coordinated with various mathematical tools [11]. In (SMC), the surface of sliding requires to be selected based on the particular aim of control, then the system is controlled towards the switching surface (the phase of approaching). At the sliding phase, the system upholds the surface of switching. When a dynamic process still stable, the system state variables are maintained on that switching surface [12]. The capability to remain at the sliding surface and maintain the states of the system on that surface refers the best quality of the (SMC). The study of robustness of the active suspension system were performed recently by many researchers using Sliding Mode Control scheme (SMC) which represents the simplest and efficient controller. The active suspension system of full vehicle with (7 Degrees of Freedom) was utilized to design SMC and this study explained that the SMC was a robust controller where it preserves the quality of the active suspensions even if the parameters (damper ratios and vehicle mass) of vehicle are changed [13]. Also, SMC scheme proposed for a non - linear full vehicle suspension system. Results compared together with the passive system and explained the effectiveness of the proposed controller [14].

The most popular control scheme is PID controller, in [15], a PID with adaptive control scheme presented for the full vehicle model with 14 degrees of freedom to minimize the unwanted movements of body in longitudinal direction through the maneuver and unexpected braking. The results explained that the designed controller was able to progress the dynamic achievement of the vehicle through the sudden acceleration and braking via different conditions. In [16], PID controller and SMC designed for controlling the suspension system. The numerical results explained the ability of the presented controller to damp the vibrations affect the internal dynamics of the vehicle and provided the safety for the vehicle. The system performance of system was compared with uncontrolled system.

Fuzzy - Skyhook control method implemented to control the full vehicle suspension system with 7 degrees of freedom and the simulation outcomes explained the ability of proposed controller to improve the quality of driving and the results shown in the domain of both frequency and time and in a comparison with the passive system [17]. In [18], authors designed a Fuzzy sliding mode controller to implement a robust controller for full vehicle active suspension system. The proposed controller handled the nonlinearities and reduced the vibrations on each side of vehicle by providing control forces to suspension system when moving on harsh road. The results explained that the proposed controller improved the dynamic response by minimizing the cost function. In [19], Linear Quadratic Regulator control (LQR) was used to test the effectiveness of full vehicle suspension system to provide the comfortable riding. The simulation outcomes utilizing two types of road profiles shown good accomplishment of suspension system. Also, the optimal LQR control method was designed to investigate the quality of the full vehicle suspension system (with 7 degrees of freedom). Results demonstrated the ability of proposed controller to minimize the vibration of pitch and roll acceleration of vehicle [20]. The performance of the suspension system such as comfortable driving, road handling and limitations of suspension motion was examined using adaptive backstepping control strategy and compared with Quadratic Lyapunov Function (QLF) [21]. Rahmi Guclu used Fuzzy Logic Control (FLC) scheme for non linear full active suspension system with 8 degrees of freedom to test the control of three cases (the passenger seat, the vertical body and both the vehicle body and the passenger seat). Simulation results explained the performance of system by comparing the three cases [22]. The problem of finite time tracking control for nonlinear mechanical systems to achieve finite time convergence has been studied in [23].

The stabilization problem via finite time control method for the suspension systems of vehicle in the presence of hard constraints depending on the Terminal Sliding Mode Control (TSMC) scheme was presented in [24]. A new second order SMC algorithm was used in order to avoid the main troubles of TSMC scheme. The performance of the suspension system was improved through satisfying the stabilization requirements for perturbed vehicle suspension system by using the finite time control strategy. In many works, the SMC is integrated with the Fuzzy Logic (FL), and named as Fuzzy Sliding Mode Controller [25]-[28]. It is known that fuzzy system represents a type of an approximated function which has a maximum flexibility. This feature means that 
(FL) is utilized as a strong tool in many different control strategies [29], [30]. To deal with uncertain coefficients in suspension systems, a control technique was introduced that combines the Sliding mode and fuzzy control scheme. Numerical outcomes proved the ability of the proposed controller to improve the full vehicle suspension system under three road profiles [31]. Huang and Chen presented an adaptive SMC scheme to curb the oscillation of the sprung mass and fuzzy logic with self-tuning ability to compensate the approximation error and limiting the implementation difficulty where, the simulation results demonstrated that the performance of the designed controller was good [32]. This paper presents the proposed Adaptive Fuzzy Sliding Mode Control (AFSMC) scheme for a full vehicle active suspension system. The aim of this control scheme is to decrease the effects of disturbance on the vehicle body, as well as provide a comfortable driving and better handling of the road, in addition to the safety of passengers in the vehicle. Results shown the superior achievement of the designed control scheme when compared with SMC and passive suspension system.

The key contributions of this work are the design of an optimal Fuzzy sliding mode control scheme with FOPID controller using $\mathrm{ABC}$ algorithm and applying this control scheme for the full vehicle model with 8 degrees of freedom with very good results. AFSMC can adaptively identify the whole motions of a non - linear full vehicle suspension system without the complete knowledge about dynamic features. The proposed control scheme has some characteristics compared with the SMC method. The primary difference can be represented by the online fuzzy estimation of unknown parameters and disturbances which is used in the control law. The uncertainties are estimated by the fuzzy system and adopted to form an adaptive control law which is derived based on the analysis of Lyapunov stability concept in order to update the proposed controller parameters online which increases the response speed and guarantee the stability of the closed loop system.

\section{Modeling OF Full Vehicle SUSPENSION SySTEM}

The model of quarter vehicle was employed in many studies and dealt with system as linear model with no investigation to the nonlinearities influences like friction in dampers and springs [33], [34]. In this work, the nonlinear behavior of the system is considered. The non - linear model with eight degrees of freedom for full vehicle active suspension system is given in Fig. (1). By utilizing the second law of Newton, the differential equations that govern the motions of the vertical displacements of the sprung mass $\left(Z_{c}\right)$, rolling rotation motion angle $(\alpha)$ and body pitching angle $(\varphi)$ are implemented as follows:

$$
\begin{gathered}
M_{s} \ddot{Z}_{c}=-\sum_{j=1}^{4} F_{k j}-\sum_{j=1}^{4} F_{c j}+\sum_{j=1}^{4} F_{j} \\
J_{x} \ddot{\alpha}=\left(F_{k 1}-F_{k 2}-F_{k 3}+F_{k 4}\right) \frac{d}{2}+\left(F_{c 1}-F_{c 2}-F_{c 3}+\right. \\
\left.F_{c 4}\right) \frac{d}{2}+\left(F_{3}-F_{1}+F_{2}-F_{4}\right) \frac{d}{2}+T_{x} \\
J_{y} \ddot{\varphi}=\left(F_{k 3}+F_{k 4}\right) b-\left(F_{k 1}+F_{k 2}\right) a+\left(F_{c 3}+F_{c 4}\right) b- \\
\left(F_{c 1}+F_{c 2}\right) a+\left(F_{1}+F_{2}\right) a-\left(F_{3}+F_{4}\right) b+T_{y}
\end{gathered}
$$

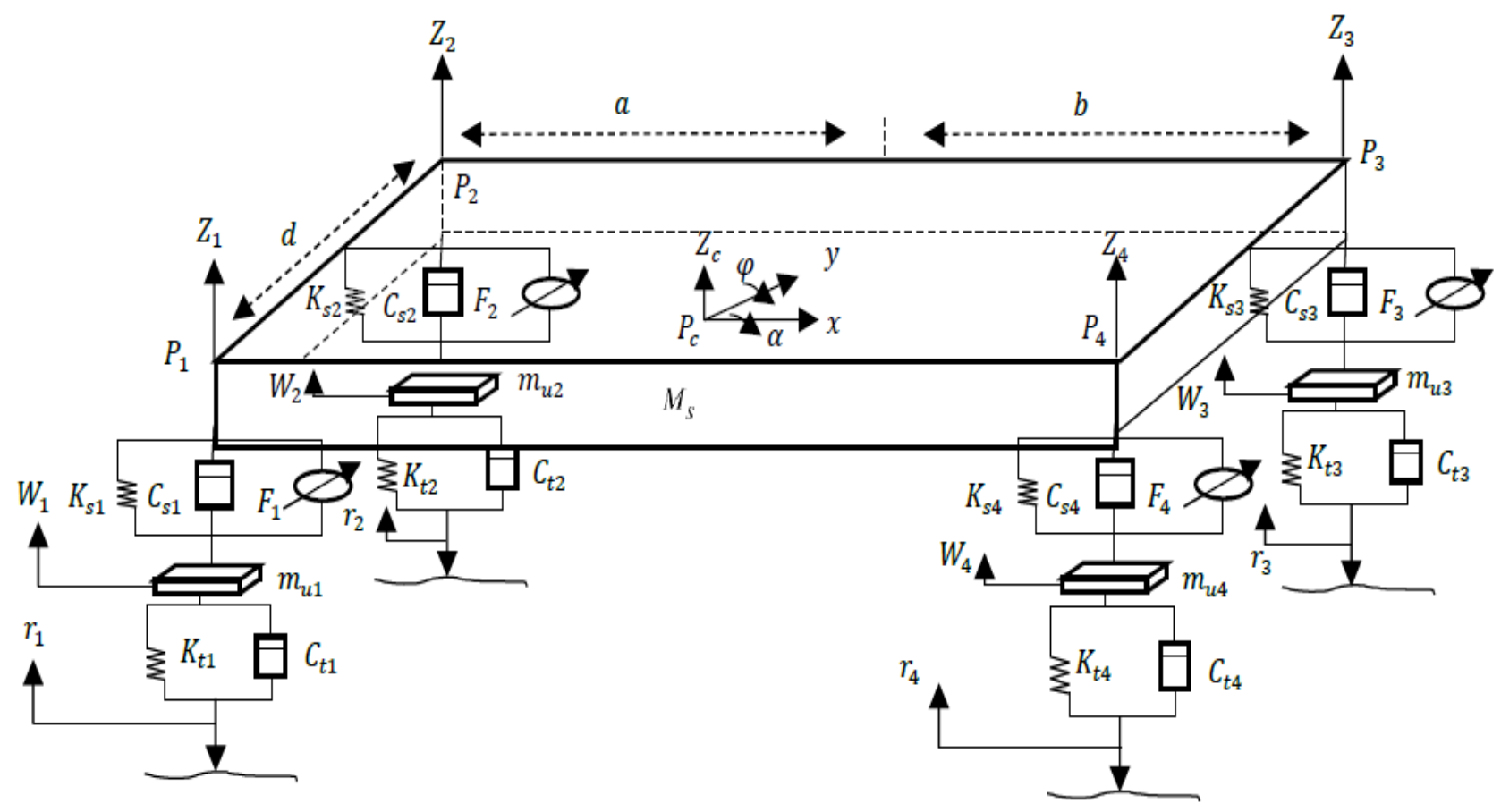

Fig. 1: Full - vehicle suspension system 
Both the inertia about each $\mathrm{x}-$ axis and $\mathrm{y}-$ axis is $\left(J_{x}, J_{y}\right)$, the mass of sprung is $M_{s}$. The bending and the braking torque are defined as $\left(T_{x}, T_{y}\right)$. The dimension between the gravity center of sprung mass and the front and rear axles are $(a, b)$ respectively and (d) is the path width. For $(j=1,2,3,4)$, the coefficients of both stiffness and damping for suspension at Front (left - right) and at Rear (right - left) are $K_{s j}, C_{s j}$ respectively. The spring force $\left(F_{k j}\right)$ and the damper force $\left(F_{c j}\right)$ are described as [21]:

$$
\begin{gathered}
F_{k j}=K_{s j}\left(Z_{j}-W_{j}\right)+\vartheta K_{s j}\left(Z_{j}-W_{j}\right)^{3} \\
F_{c j}=C_{s j}\left(\dot{Z}_{j}-\dot{W}_{j}\right)+\vartheta C_{s j}\left(\dot{Z}_{j}-\dot{W}_{j}\right)^{2} \operatorname{sgn}\left(\dot{Z}_{j}-\dot{W}_{j}\right)
\end{gathered}
$$

The generated nonlinear force $\left(F_{j}\right)$ is defined as:

$$
F_{j}=F_{h y j}-F_{f r j}
$$

Where, the nonlinear hydraulic actuator and frictional forces are $\left(F_{h y j}, F_{f r j}\right)$ respectively, $(\vartheta)$ is an empirical operator. The hydraulic actuator force is defined as:

$$
F_{h y j}=A_{p} P_{L j}
$$

The differential equation of the $j^{\text {th }}$ actuator's piston pressure $\left(P_{L j}\right)$ can be written as:

$$
\begin{gathered}
\dot{P}_{L j}=-\sigma A_{p}\left(\dot{Z}_{j}-\dot{W}_{j}\right)-\beta P_{L j} \\
x_{v j} \gamma \sqrt{P_{\text {sup }}-\operatorname{sgn}\left(x_{v j}\right) P_{L j}}
\end{gathered}
$$

The dynamic equation of the voltage input signal $\left(u_{p j}\right)$ that used to control the servo - valve displacement of spool $\left(x_{v j}\right)$ is described as:

$$
\dot{x}_{v j}=\frac{1}{\tau}\left(K_{c} u_{p j}-x_{v j}\right)
$$

Where, $(\sigma, \beta$ and $\gamma)$ are the actuator parameters, the piston area is $\left(A_{p}\right),\left(P_{\text {sup }}\right)$ represents pressure supply of the pump, the conversion gain is $\left(K_{c}\right)$ and $(\tau)$ is the time of the mechanical delay of the system. The frictional force cannot be ignored, and implemented with signum function approximation as:

$F_{f r j}=\left\{\begin{array}{lll}\psi \operatorname{sgn}\left(\dot{Z}_{j}-\dot{W}_{j}\right) & \text { for } & \left|\left(\dot{Z}_{j}-\dot{W}_{j}\right)\right| \geq 0.01 \\ \psi \sin \frac{\pi\left(\dot{Z}_{j}-\dot{W}_{j}\right)}{0.02} & \text { for } & \left|\left(\dot{Z}_{j}-\dot{W}_{j}\right)\right|<0.01\end{array}\right.$

Where, $(\psi)$ is an empirical factor. For $(j=1,2,3,4)$, and $W_{j}$ is the vertical displacements of unsprung mass at Front (left - right), Rear (right - left) respectively and its motion can be defined as:

$$
m_{u j} \ddot{W}_{j}=-K_{t j}\left(W_{j}-r_{j}\right)-C_{t j}\left(\dot{W}_{J}-\dot{r}_{j}\right)+F_{k j}+F_{c j}-
$$

Where, $\mathrm{m}_{\mathrm{uj}}, K_{t j}$ and $C_{t j}$ are the unsprung mass, the coefficients of tire's stiffness and tire's damping in the Front (left - right) and in the Rear (right - left) respectively. The road profile is $r_{j}$. The vertical displacement of the sprung mass $\left(Z_{j}\right)$ according to the rigid body movement law at the points $\left(P_{1}, P_{2}, P_{3}\right.$, and $\left.P_{4}\right)$ with respect to $Z_{c}, \alpha$, and $\varphi$ can be expressed as given in [35] as:

$$
\begin{aligned}
& Z_{1}=Z_{c}-0.5 d \alpha-a \varphi ; Z_{2}=Z_{c}+0.5 d \alpha-a \varphi \\
& Z_{3}=Z_{c}+0.5 d \alpha+a \varphi ; Z_{4}=Z_{c}-0.5 d \alpha+a \varphi
\end{aligned}
$$

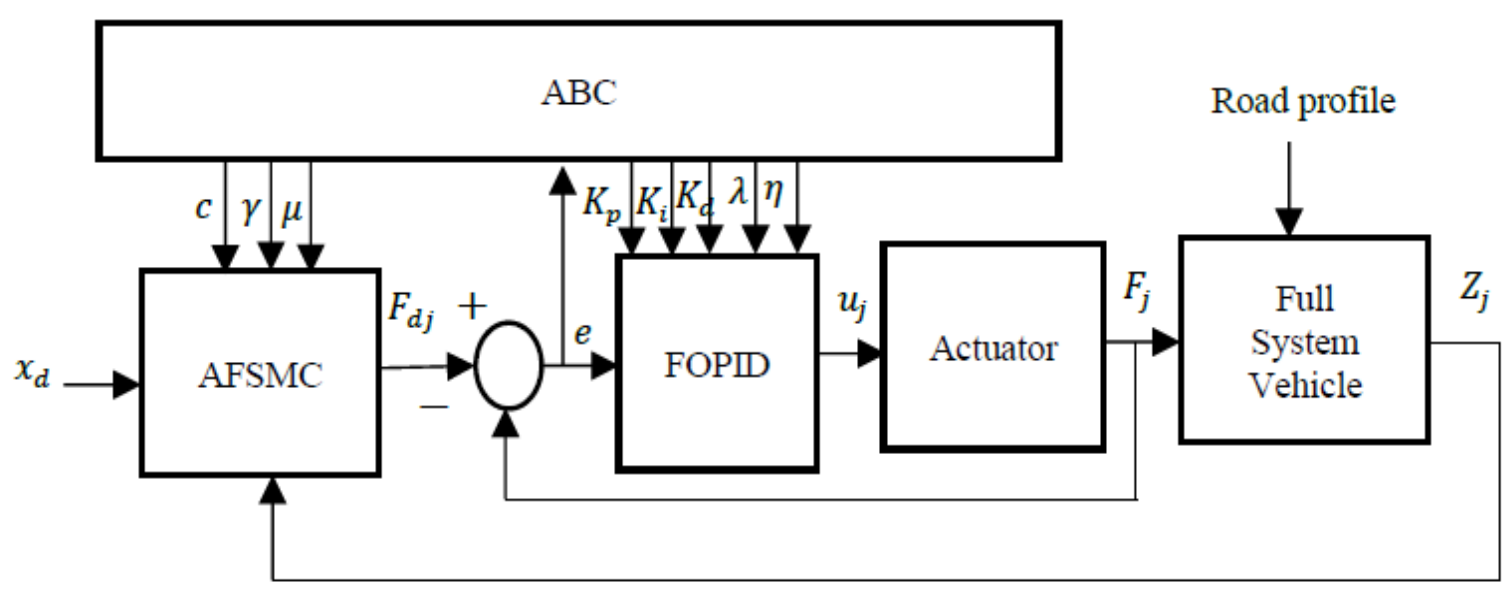

Fig. 2: Block Diagram of Proposed Control Scheme 


\section{The Proposed CONTROL SCHEME}

The aim of the design of a controller for the suspension system of vehicle is to decrease the vibration in the cabin caused by road roughness and to support the handling of the road. This needs a controller of accurate and fast specifications to achieve these objectives. The proposed control scheme will be adopted to achieve these requirements efficiently. This control scheme has been depicted schematically in Fig. (2). The design of four similar sub controllers, one for each side of wheels is implemented. Each sub control scheme consists of an Adaptive Fuzzy Sliding Mode Controller (AFSMC) in the outer loop and a FOPID controller in the inner loop. Fuzzy system is widely used as controller or as estimator in a lot of applications [36][41]. This study collects both the fuzzy system and the Sliding Mode controller to estimate the uncertain parameters and limit the nonlinearity of the system.

The FOPID controller is designed to control the actuator force and create the required force estimated through the proposed controller.

On the other hand, all parameters of each controller have been optimized with $\mathrm{ABC}$ to get the optimal values for parameters $\left(K_{p}, K_{i}, K_{d}, \lambda, \eta c, \gamma\right.$ and $\left.\mu\right)$ gains. The desired signal $\left(x_{d}\right)$ is assumed equal to zero and the applied road profile is considered a random signal.

\section{A. Adaptive Fuzzy Sliding Mode Control}

The Minimum Parameter Learning (MPL) technique is a self -learning method for the parameters in the system [42]. In this work a fuzzy estimator is used to estimate the unknown and uncertain nonlinear parts of the system using (MPL). The systems can be considered uncertain system, where the dynamics of the system are varying under different conditions. In order to design the sub control scheme for each side, the dynamic equation at each side $(j=1,2,3,4)$ can be modeled as:

$$
\begin{gathered}
M_{s j} \ddot{Z}_{j}+F_{k j}+F_{c j}-F_{j}=0 \\
m_{u j} \ddot{W}_{j}+K_{t j}\left(W_{j}-r_{j}\right)+C_{t j}\left(\dot{W}_{j}-\dot{r}_{j}\right)-F_{k j}-F_{c j}+F_{j}=0
\end{gathered}
$$

For each of the four sides, the body displacement is denoted as $x_{1}=Z_{j}$, the velocity of the body is denoted as $x_{2}=\dot{Z}_{j}$, the unsprung mass displacement is $x_{3}=W_{j}$ and the velocity of the unsprung mass is $x_{4}=\dot{W}_{j}$, the vector $x=$ $\left[x_{1}, x_{2}, x_{3}, x_{4}\right]^{T}$ is the state form of the system. The body vertical motion at each side $(j)$ can be described as:

$$
\ddot{x}_{1}=f(x, t)+\frac{1}{M_{s j}} F_{j}
$$

The unknown function $f(x, t)$ to be approximated and estimated is:

$$
f(x, t)=\frac{1}{M_{s j}}\left(-F_{k j}-F_{c j}\right)
$$

In the following we will change $f(x, t)$ with $\hat{f}(x, t)$ to realize the control law, where, the following formulation defines the output of the fuzzy system as:

$$
\hat{f}\left(x \mid \theta_{f}\right)=\frac{\sum_{l_{1}=1}^{5} \sum_{l_{2}=1}^{5} \Sigma_{l_{3}=1}^{5} \Sigma_{l_{4}=1}^{5} y_{f}^{l_{1} l_{2} l_{3} l_{4}}\left(\prod_{i=1}^{4} \mu_{A_{i}}^{l_{i}}\left(x_{i}\right)\right)}{\sum_{l_{1}=1}^{5} \sum_{l_{2}=1}^{5} \sum_{l_{3}=1}^{5} \sum_{l_{4}=1}^{5}\left(\prod_{i=1}^{4} \mu_{A_{i}}^{l_{i}}\left(x_{i}\right)\right)}
$$

Where; $\mu_{A_{i}}^{l_{i}}\left(x_{i}\right)$ is the membership function of $x_{i}$, which is a Gaussian function and defined as:

$$
\begin{gathered}
\mu_{N M}\left(x_{i}\right)=\exp \left[-\left(\left(x_{i}+\frac{\pi}{3}\right) /\left(\frac{\pi}{12}\right)\right)^{2}\right] \\
\mu_{N S}\left(x_{i}\right)=\exp \left[-\left(\left(x_{i}+\frac{\pi}{6}\right) /\left(\frac{\pi}{12}\right)\right)^{2}\right] \\
\mu_{Z}\left(x_{i}\right)=\exp \left[-\left(x_{i} /\left(\frac{\pi}{12}\right)\right)^{2}\right] \\
\mu_{P S}\left(x_{i}\right)=\exp \left[-\left(\left(x_{i}-\frac{\pi}{6}\right) /\left(\frac{\pi}{12}\right)\right)^{2}\right] \\
\mu_{N M}\left(x_{i}\right)=\exp \left[-\left(\left(x_{i}-\frac{\pi}{3}\right) /\left(\frac{\pi}{12}\right)\right)^{2}\right]
\end{gathered}
$$

Where, $y_{f}^{l_{1} l_{2} l_{3} l_{4}}$ is a parameter in the group $\hat{\theta}_{f} \in R u l e^{(625)}$, and fuzzy rules form column vector for $p_{1}=p_{2}=p_{3}=$ $p_{4}=5, \xi(x)=\prod_{i=1}^{4} p_{i}=p_{1} \times p_{2} \times p_{3} \times p_{4}=625$ are:

Rule ${ }^{(1)}$ : If $x_{1}$ is $A_{1}^{1}$ and $x_{2}$ is $A_{2}^{1}$ and $x_{3}$ is $A_{3}^{1}$ and $x_{4}$ is $A_{4}^{1}$ then $\hat{f}$ is $B^{1}$, to.....

Rule ${ }^{(625)}:$ If $x_{1}$ is $A_{1}^{5}$ and $x_{2}$ is $A_{2}^{5}$ and $x_{3}$ is $A_{3}^{5}$ and $x_{4}$ is $A_{4}^{5}$ then $\hat{f}$ is $B^{625}$.

The fuzzy sets $A_{1}^{l_{i}}, A_{2}^{l_{i}}, A_{3}^{l_{i}}$, and $A_{4}^{l_{i}}$ respectivel, $l_{i}=$ $1,2,3,4,5$. According to (14), the fuzzy output can be changed to:

$$
\begin{gathered}
\hat{f}\left(x \mid \theta_{f}\right)=\hat{\theta}^{T} \xi(x) \\
\xi_{l_{1} l_{2} l_{3} l_{4}}(x)=\frac{\prod_{i=1}^{4} \mu_{A_{i}}^{l_{i}}\left(x_{i}\right)}{\sum_{l_{1}=1}^{p_{1}} \Sigma_{l_{2}=1}^{p_{2}} \Sigma_{l_{3}=1}^{p_{3}} \Sigma_{l_{4}=1}^{p_{4}}\left(\Pi_{i=1}^{4} \mu_{A_{i}}^{l_{i}}\left(x_{i}\right)\right)}
\end{gathered}
$$

The minimum error can be defined by $\theta_{f}^{*}$ parameter as:

$$
\theta_{f}^{*}=\arg \min _{\theta_{f} \in \Omega_{f}}\left[\sup \left|\hat{f}\left(x \mid \theta_{x \in R^{n}}\right)-f(x)\right|\right]
$$

Where, $\Omega_{f}$ is a limited set of $\theta_{f}$. The term $(f)$ can be described as:

$$
f=\theta_{f}^{* T} \xi(x)+\varepsilon
$$


Where $\varepsilon$ is an estimation error of the fuzzy system, express a positive constant as $\phi=\left\|\theta_{f}^{*}\right\|^{2}$ and let $\hat{\phi}$ be an estimate of $\phi$, the approximation $(f)$ :

$$
\hat{f}\left(x \mid \theta_{f}\right)=\hat{\theta}_{f}^{T} \xi(x)
$$

The Lyapunov function will be characterized in this work is:

$$
V=\frac{1}{2} s^{2}+\frac{1}{2 \gamma} \tilde{\phi}^{2}
$$

Where; $\tilde{\phi}=\hat{\phi}-\phi$ and $\gamma$ is positive.

$$
\dot{V}=s \dot{S}+\frac{1}{\gamma} \tilde{\phi} \dot{\phi}
$$

The adaptive law is designed as:

$$
\dot{\hat{\phi}}=\frac{\gamma}{2} s^{2} \xi^{T} \xi-\kappa \gamma \hat{\phi}
$$

Where, $\kappa>0$. Then,

$$
\begin{gathered}
\dot{V} \leq-\kappa \tilde{\phi} \hat{\phi}+\frac{1}{2}-\mu s^{2}\left(\tilde{\phi}^{2}-\phi^{2}\right)+\frac{1}{2}-\mu s^{2} \\
=-\frac{\kappa}{2} \tilde{\phi}^{2}-\mu s^{2}+\left(\frac{\kappa}{2} \phi^{2}+\frac{1}{2}\right)
\end{gathered}
$$

By defining $\kappa=\frac{2 \mu}{\gamma}$, and $\mu>0$.

$$
\begin{aligned}
\dot{V} \leq & -\frac{\mu}{\gamma} \tilde{\phi}^{2}-\mu s^{2}+\left(\frac{\kappa}{2} \phi^{2}+\frac{1}{2}\right) \\
& =-\left(\frac{1}{2 \gamma} \phi^{2}+\frac{1}{2} s^{2}\right)+\left(\frac{\kappa}{2} \phi^{2}+\frac{1}{2}\right) \\
& =-2 \mu V+Q
\end{aligned}
$$

Solving $\dot{V} \leq-2 \mu V+Q$, where, $Q=\frac{\kappa}{2} \phi^{2}+\frac{1}{2}$ to give:

$$
\lim _{t \rightarrow \infty} V=\frac{Q}{2 \mu}=\frac{\frac{\kappa}{2} \phi^{2}+\frac{1}{2}}{2 \mu}=\frac{\kappa \phi^{2}+1}{4 \mu}=\frac{\frac{2 \mu}{\gamma} \phi^{2}+1}{4 \mu}=\frac{\phi^{2}}{2 \gamma}+
$$

$\frac{1}{4 \gamma}$

According to the sliding function formulation:

$$
s=\dot{e}+c e
$$

The convergent rate of $x_{1}$ is, and $c>0$. The tracking error can be defined as:

$$
\begin{gathered}
e=x_{1}-x_{d} \\
\dot{s}=\ddot{e}+c \dot{e}=\ddot{x}_{1}-\ddot{x}_{d}+c \dot{e}=f(x, t)+\frac{1}{M_{s j}} F_{d j}+c \dot{x}_{1}
\end{gathered}
$$

Lastly, the AFSMC law can be designed as:

$$
F_{d j}=M_{s j}\left(-\frac{1}{2} s \hat{\phi} \xi^{T} \xi-c \dot{x}_{1}-\mu s\right)
$$

From (27), it can be shown that the accuracy of convergence is based on $(c, \gamma$ and $\mu$ ) parameters. The sliding surface converges to zero lastly.

\section{B. The Optimization of Parameters of the Proposed Control Scheme Using ABC Algorithm}

The traditional of (PID) controller is the most widely type of controllers that have been used in industry, but the recent progressing in the fractional calculus introduce implementations of the fractional order calculus in the theory of control. The main applications of the fractional calculus are the Fractional Order PID (FOPID) controller and this type of controller has received more attention in both industrial applications and academic studies. [43].

The FOPID controller can improve the stabilization for the system and give a suitable system performance. It is possible to improve the performance of PID controller by employing the Fractional Order $\left(\mathrm{PI}^{\lambda} \mathrm{D}^{\eta}\right)$ with real order of integral and derivative terms where these orders make the FOPID more flexible. It is greatly used in different application [44]-[46]. The equation of the FOPID controller is defined as:

$$
u_{j}=K_{p} e(t)+K_{i} D_{t}^{-\lambda} e(t)+K_{d} D_{t}^{\eta} e(t)
$$

Where; $\left(u_{j}\right)$ is the output of FOPID controller. The parameters $\left(K_{p}, K_{i}\right.$, and $\left.K_{d}\right)$ denote the proportional, the integral and the derivative gains respectively and the orders ( $\lambda$ and $\eta$ ) may be any real values. The FOPID controller seeks to reduce the error $\left(e=F_{d j}-F_{j}\right)$. The desired force $\left(F_{d j}\right)$ is generated by AFSMC and the actual actuated force is $\left(F_{j}\right)$. In order to obtain the optimal values for $\left(K_{p}, K_{i}, K_{d}\right.$, $\lambda, \eta, c, \gamma$ and $\mu$ ) for the FOPID controller and AFSMC parameters respectively, the Artificial Bee Colony (ABC) algorithm has been utilized which was firstly proposed via Dervis Karaboga in 2005 [47].

The optimization technique (ABC) is an algorithm inspired by nature depending on the bee colonies behavior, where these colonies are employed or unemployed bees. The employed bees search about the good source's places of food, store the related information about it and share this information with the bees of hive. Any of the food sources will represent an optimization solution for the problem, the nectar amount matches to the solution fitness.

The second group of the bee colony is the unemployed bees which involve both onlooker bees and scout bees. The 
onlooker bees decide the selection of the superior source of food depending on the information founded by employed bees [48], [49]. On the other hand, the food sources are examined by the scout bees, if it becomes deserted, the employed bees will be considered as a scout and then inspection about another sustenance source.

The ABC method used in this study can find suitable gain parameters for the proposed controller in order to decrease the amount of suspension, acceleration and displacement of the vehicle body. In ABC optimization method, the fitness function which is selected to contain one or more terms of the cost functions like:

$$
\begin{gathered}
\cos t_{1}=\sum_{i=1}^{4} \sum_{i=1}^{N} Z_{j i}^{2}+\ddot{Z}_{j i}^{2} \\
\cos t_{2}=\sum_{i=1}^{4} \sum_{i=1}^{N}\left(Z_{j i}-W_{j i}\right)^{2} .
\end{gathered}
$$

The flowchart involves the basic steps of $\mathrm{ABC}$ representation can be explained in Fig. (3) [50], [51].

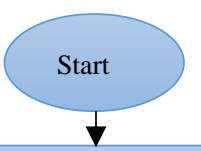

Read and initialize the $\mathrm{ABC}$ and system data such as (parameter limits, maximum number of cycles, colony dimension)

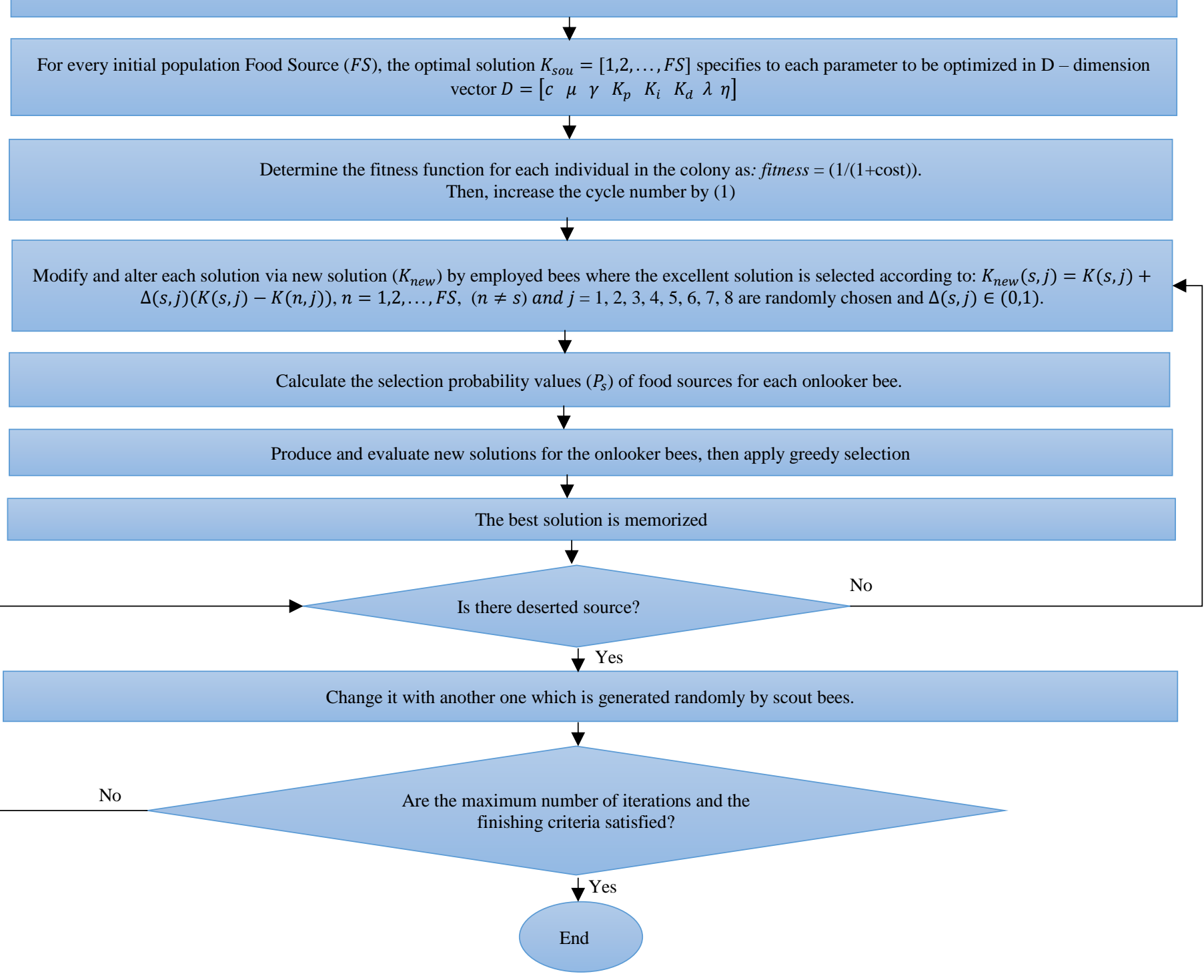

Fig. 3: Flowchart of ABC algorithm 


\section{THE RESULTS}

In this section, the full vehicle model given in Fig. (1) with a random input road profile is considered. A set of parameters explained in Table (I) and Table (II) describe the parameters of both hydraulic actuator and the full vehicle suspensions. The goodness and effectiveness of the proposed control scheme will be tested and compared with conventional Sliding Mode Control scheme (SMC) and passive suspension system. Computer simulations using the MATLAB/SIMULINK are described to show the quality of the proposed control strategy. At each side, the suspension system, AFSMC and FOPID controllers are used.

The outputs of FOPID controllers $\left(u_{1}, u_{2}, u_{3}\right.$, and $\left.u_{4}\right)$ are utilized to control the hydraulic actuator force $\left(F_{j}\right)$ of each suspension system in each side. The AFSMC scheme in each side will produce the desired force $\left(F_{d j}\right)$.

TABLE I

THE HYDRAULIC ACTUATOR PARAMETERS

\begin{tabular}{|c|c|}
\hline Sample & Values \\
\hline$\sigma$ & $4.515 \times 10^{13}$ \\
\hline$\beta$ & 1 \\
\hline$\gamma_{s}$ & $1.545 \times 10^{9}$ \\
\hline$P_{\text {sup }}$ & $3.35 \times 10^{-4}$ \\
\hline$A_{p}$ & $0.001(\mathrm{~m} / \mathrm{V})$ \\
\hline$K_{c}$ & $1 / 30(\mathrm{~s})$ \\
\hline$\tau$ & \\
\hline
\end{tabular}

The ABC technique is utilized to compute the optimized values of the proposed controller parameters. The parameters selected for ABC algorithm are given in Table (III). To minimize the optimization time, the proposed controller parameters are selected in the ranges: $K_{p}, K_{i}$, and $K_{d} \in[1$ 500]; $c$ and $\mu \in$ [1 10]; $\gamma, \lambda$, and $\eta \in\left[\begin{array}{ll}0 & 1\end{array}\right]$ for the four-sub control scheme.

Five Gaussian membership function with centers $\left(\mu_{1}=1\right.$, $\mu_{2}=0.5, \mu_{3}=0, \mu_{4}=-0.5$, and $\mu_{5}=-1$ ) are used as an input to the fuzzy estimator as shown in Fig. (4).

After ABC optimization algorithm, the optimal values for parameters of each proposed controller $\left(C_{1}, C_{2}, C_{3}\right.$ and $\left.C_{4}\right)$ are demonstrated in Table (IV).
TABLE II

THE FULL VEHICLE SYSTEM PARAMETERS

\begin{tabular}{|c|c|}
\hline Parameter & Value \\
\hline$M_{s}$ & $1460(\mathrm{~kg})$ \\
\hline$J_{x}$ & $460\left(\mathrm{~kg} \cdot \mathrm{m}^{2}\right)$ \\
\hline$J_{y}$ & $2460\left(\mathrm{~kg} \cdot \mathrm{m}^{2}\right)$ \\
\hline$d$ & $1.51(\mathrm{~m})$ \\
\hline$a$ & $1.011(\mathrm{~m})$ \\
\hline$b$ & $1.803(\mathrm{~m})$ \\
\hline$K_{s 1}, K_{s 2}$ & $19960(\mathrm{~N} / \mathrm{m})$ \\
\hline$K_{s 3}, K_{s 4}$ & $17500(\mathrm{~N} / \mathrm{m})$ \\
\hline$C_{s 1}, C_{s 2}$ & $1290(\mathrm{~N} . \mathrm{s} / \mathrm{m})$ \\
\hline$C_{s 3}, C_{s 4}$ & $1620(\mathrm{~N} . \mathrm{s} / \mathrm{m})$ \\
\hline$M_{u 1}, M_{u 2}$ & $40(\mathrm{~kg})$ \\
\hline$M_{u 3}, M_{u 4}$ & $35.5(\mathrm{~kg})$ \\
\hline$M_{s j}$ & $290(\mathrm{~kg})$ \\
\hline$K_{t 1}, K_{t 2}, K_{t 3}, K_{t 4}$ & $175500(\mathrm{~N} / \mathrm{m})$ \\
\hline$C_{t 1}, C_{t 2}, C_{t 3}, C_{t 4}$ & $14.6(\mathrm{~N} . \mathrm{s} / \mathrm{m})$ \\
\hline$\psi, \vartheta$ & 0.1 \\
\hline
\end{tabular}

TABLE III

ABC ALGORITHM PARAMETERS

\begin{tabular}{|c|c|}
\hline Parameter & Value \\
\hline Number of optimization parameters & 8 \\
\hline Maximum number of iteration cycle & 50 \\
\hline Colony dimension & 100 \\
\hline Number of Food Source & 50 \\
\hline
\end{tabular}

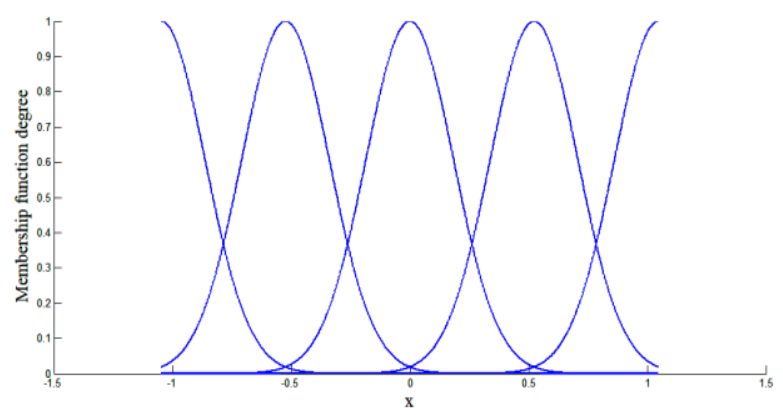

Fig. 4: Membership function of $x_{i}$

TABLE IV

THE OPTIMAL VALUES OF THE FOUR SUB PROPOSED CONTROLLER

\begin{tabular}{|c|c|c|c|c|c|c|c|c|}
\hline Controller & $K_{p}$ & $K_{i}$ & $K_{d}$ & $\lambda$ & $\eta$ & $c$ & $\gamma$ & $\mu$ \\
\hline$C_{1}$ & 339.0463 & 327.3944 & 137.7384 & 0.88 & 0.97 & 7.23 & 0.04 & 2.68 \\
\hline$C_{2}$ & 378.6278 & 84.7645 & 22.1319 & 0.47 & 0.8 & 3.85 & 0.03 & 5.47 \\
\hline$C_{3}$ & 371.3094 & 352.7291 & 47.663 & 0.87 & 0.75 & 9.55 & 0.07 & 5.01 \\
\hline$C_{4}$ & 195.5057 & 14.9483 & 411.5524 & 0.47 & 0.77 & 1.31 & 0.09 & 6.81 \\
\hline
\end{tabular}


Also, a bending torque and braking torque $\left(T_{x}, T_{y}\right)$ as shown in Fig. (5) and Fig. (6) have been applied to the full vehicle active suspension system and taken into consideration.

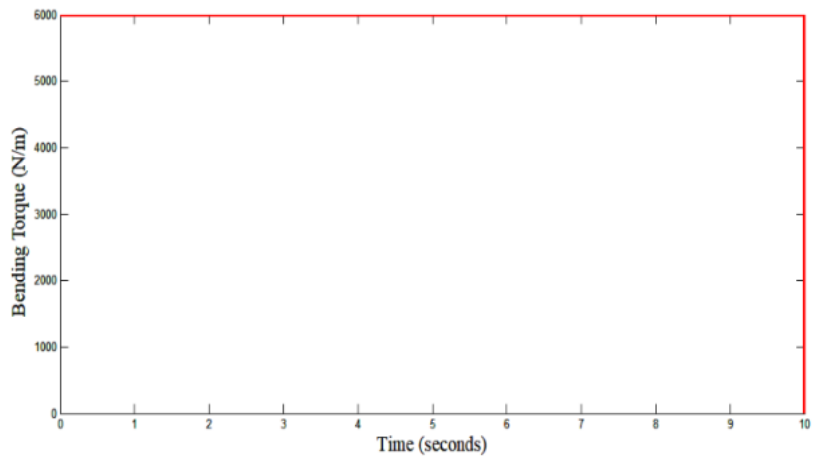

Fig. 5: Bending Torque

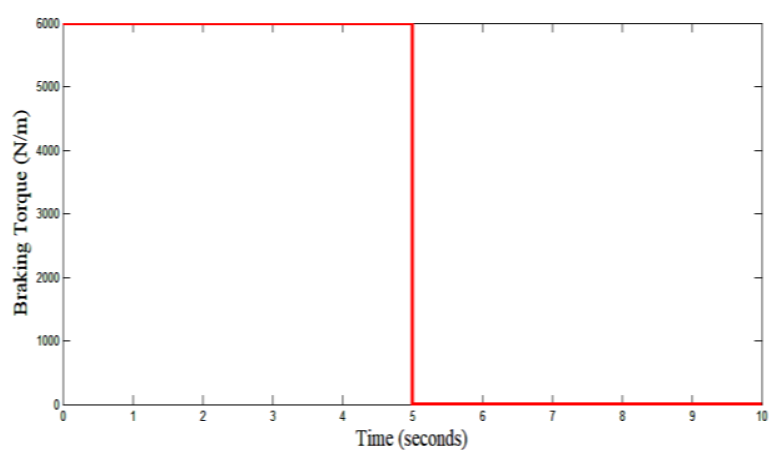

Fig. 6: Braking Torque

The responses of full vehicle active suspension system via proposed control scheme (AFSMC and FOPID optimized with $\mathrm{ABC}$ ) are given in together with both using SMC and passive suspension system. Less amplitudes of vertical displacement signals of the body vehicle are evident and converged to nearly zero by proposed control scheme as shown in Fig. (7). Also, one can notice that the motions of the wheel's mass track the different irregular road paths.

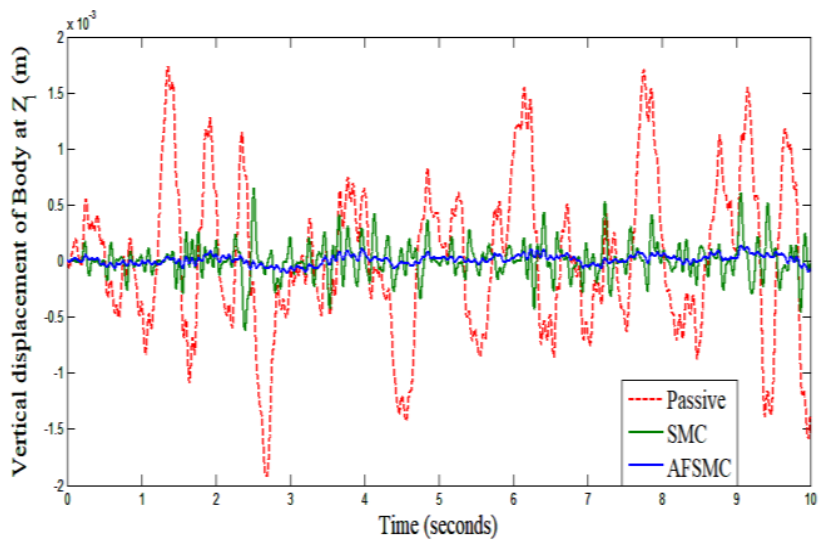

(i)

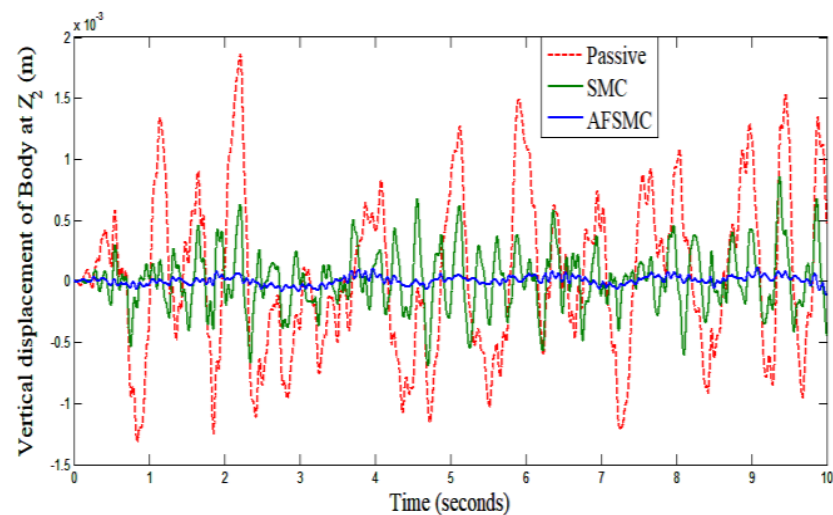

(ii)

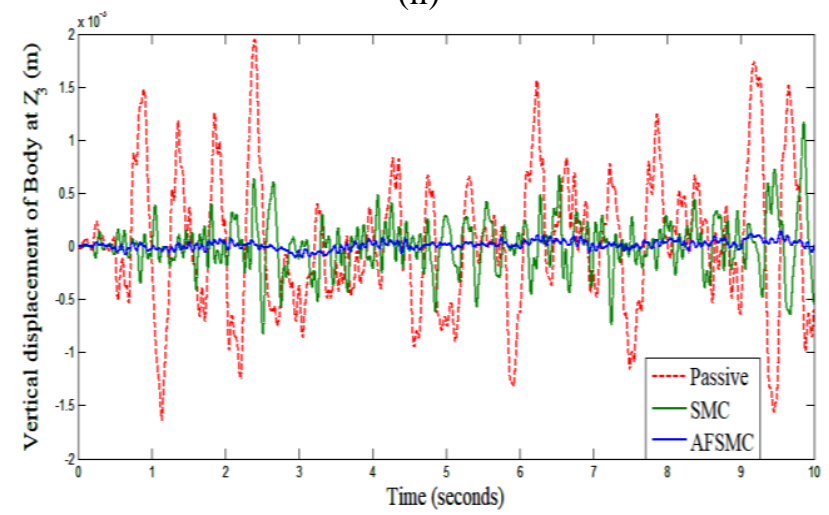

(iii)

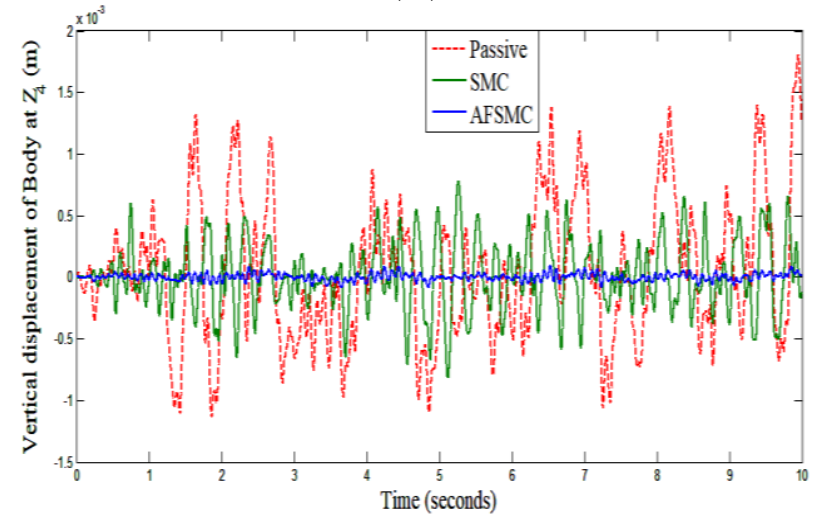

(iv)

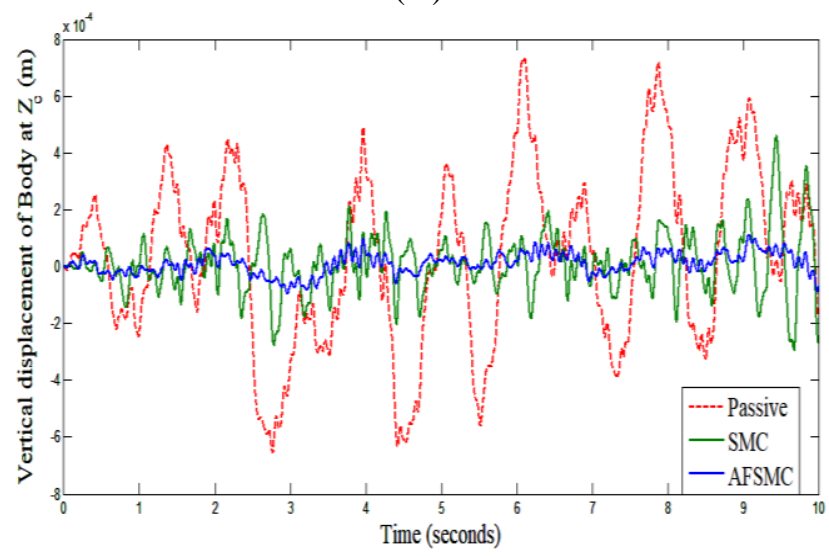

(v)

Fig.7: Displacement and rotation of Body at: (i): $Z_{1}$, (ii): $Z_{2}$, (iii): $Z_{3}$, (iv): $Z_{4}$, (v): $Z_{c}$, (vi): $\alpha$, (vii): $\varphi$. 


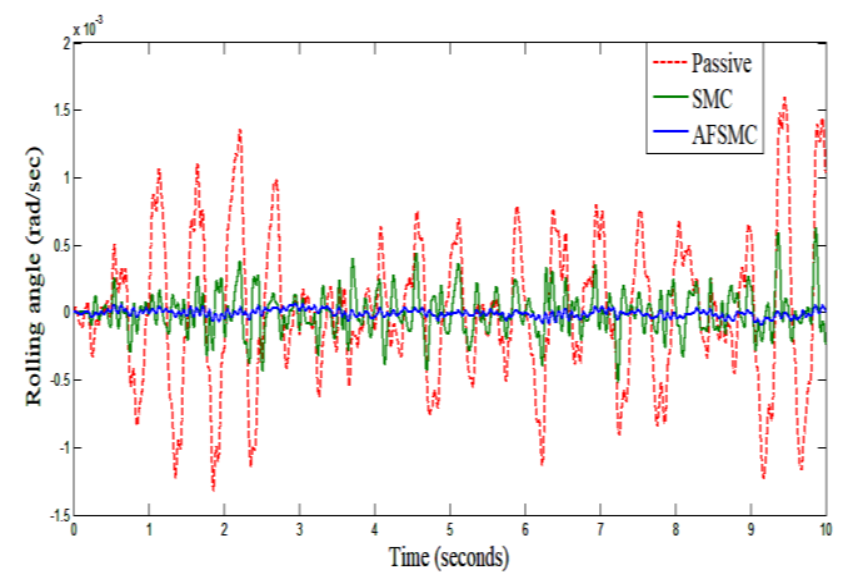

(vi)

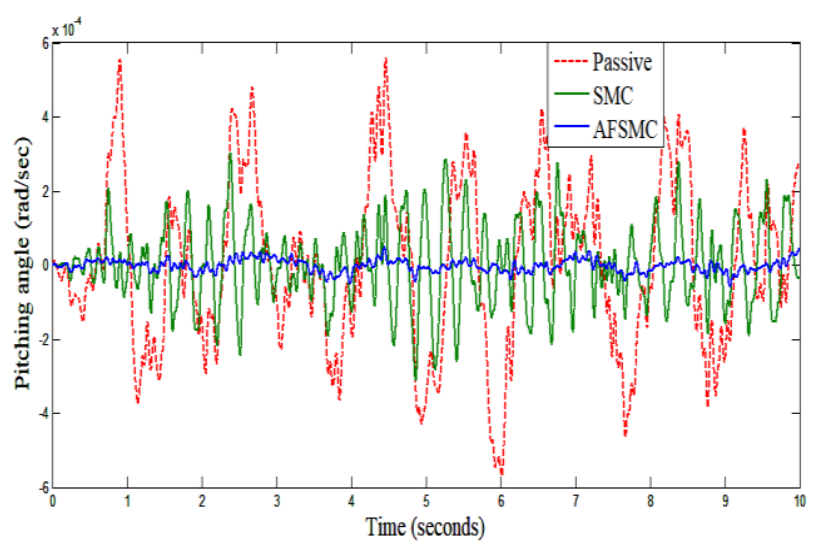

(vii)

Fig. 7: Continued.

Values of vehicle acceleration signals as shown in Fig. (8) is significatively reduced which gives better result of the proposed control strategy when compared with SMC and passive system. After applying Bending and Braking Torques, the output responses for the full vehicle suspension system controlled via proposed control scheme compared with the SMC and passive suspension system, as shown in Fig. (9) and Fig. (10).

These figures explained that the transient of the sprung mass displacement have been effectively minimized. Furthermore, a best contact between the road and the tire to give good guidance along the path is achieved.

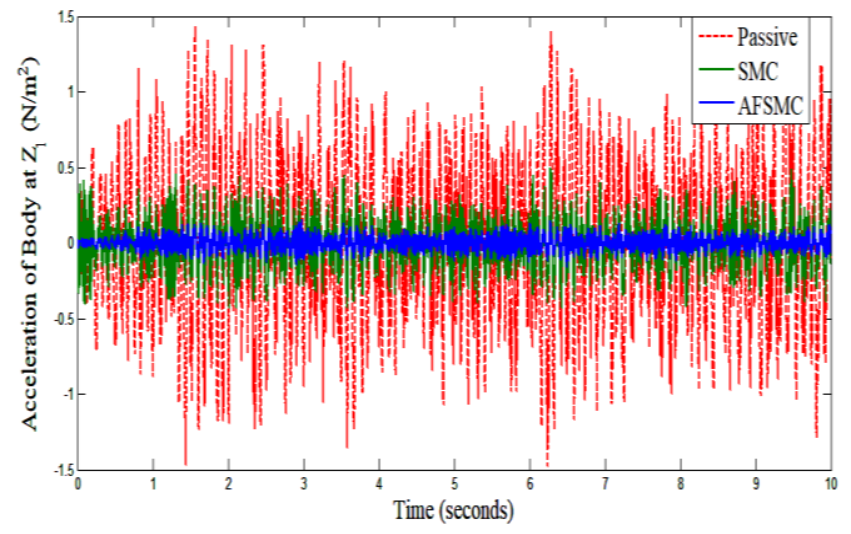

(i)

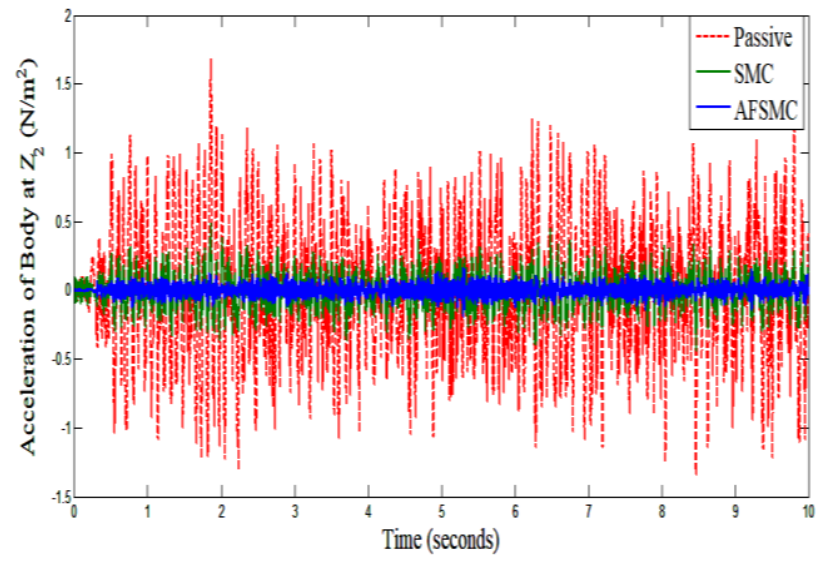

(ii)

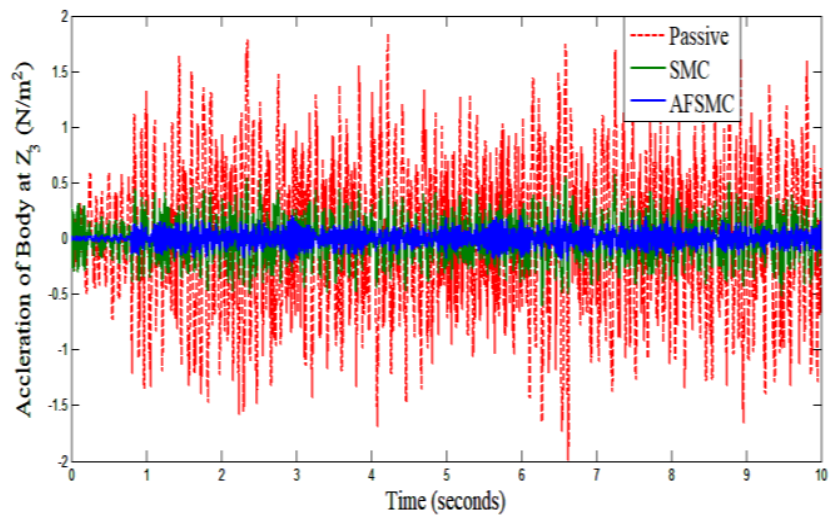

(iii)

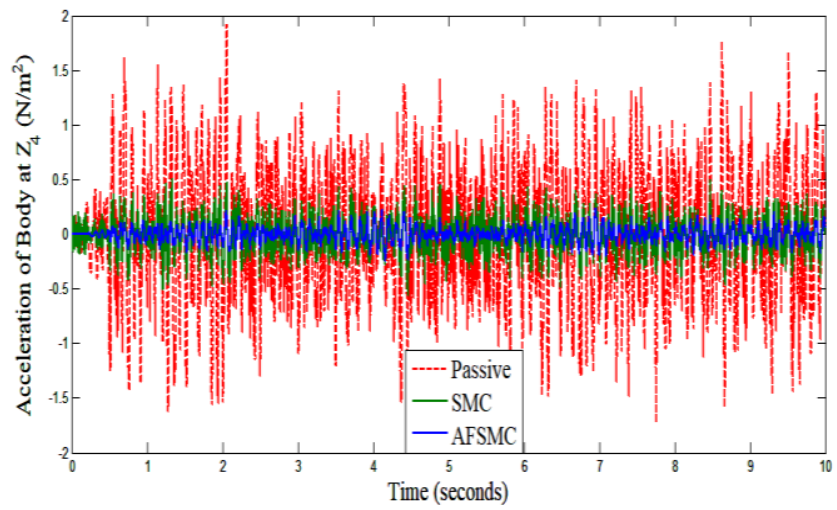

(iv)

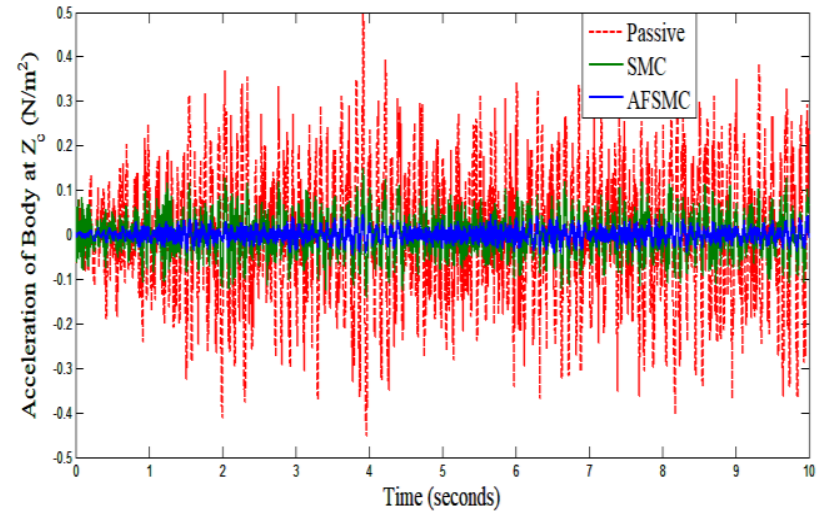

(v)

Fig. 8: Acceleration of Body at: (i): $Z_{1}$, (ii): $Z_{2}$, (iii): $Z_{3}$, (iv): $Z_{4}$, (v): $Z_{c}$ 


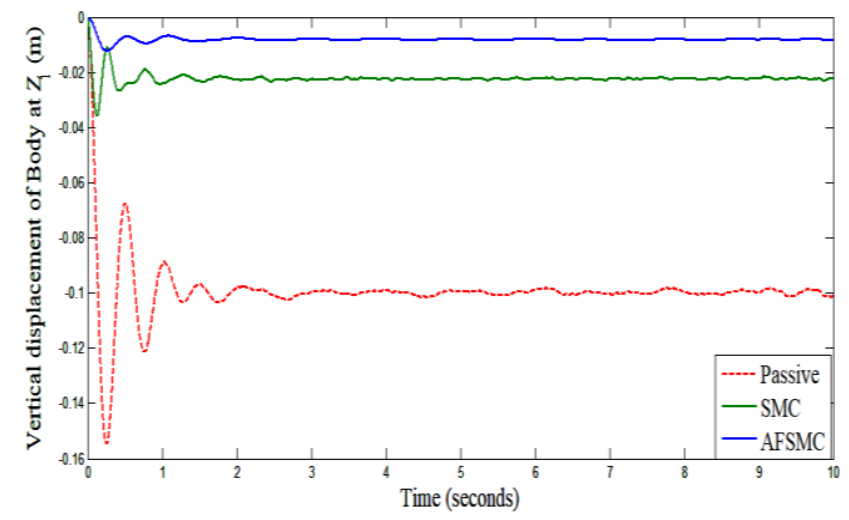

(i)

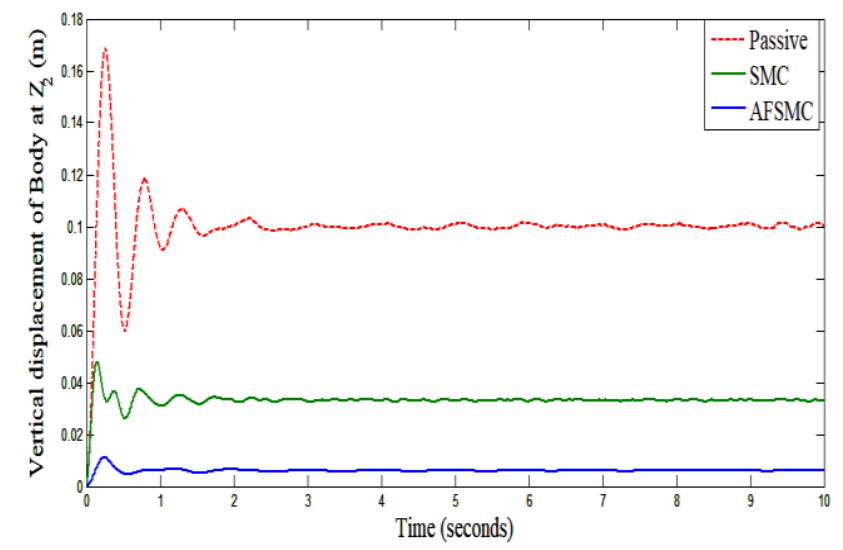

(ii)

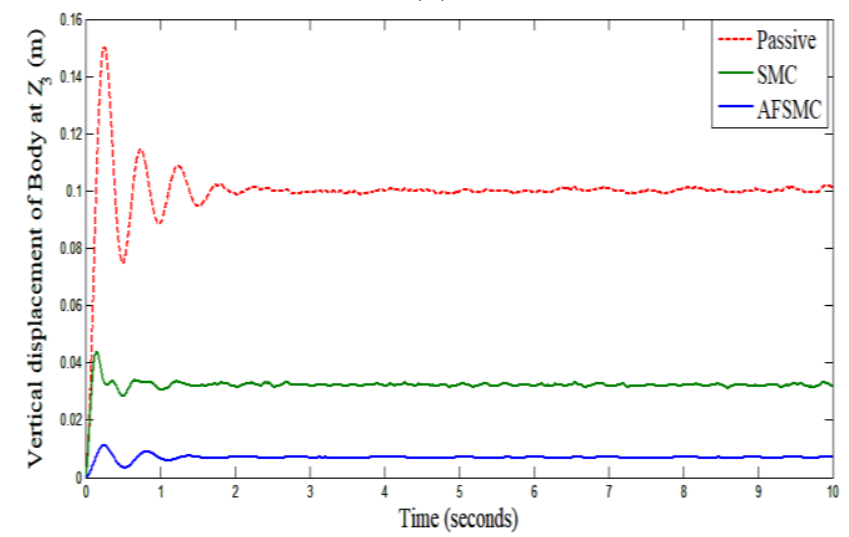

(iii)

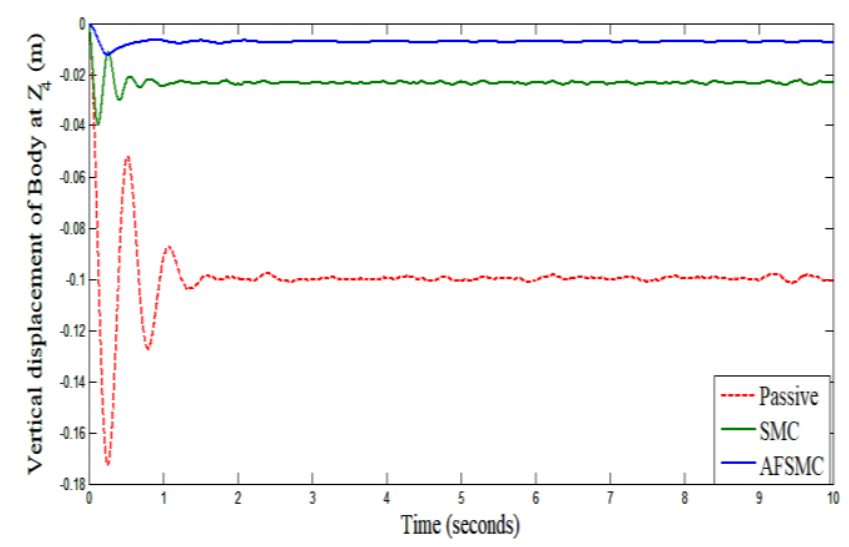

(iv)

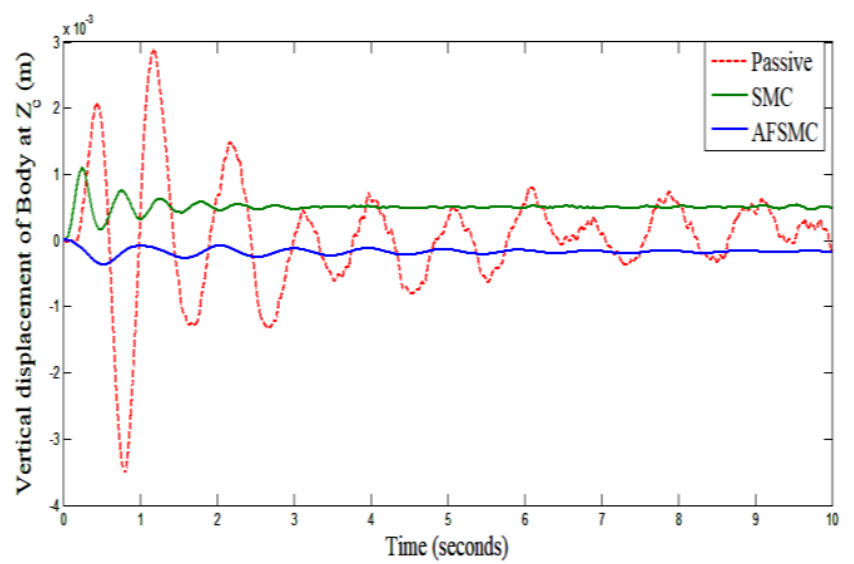

(v)

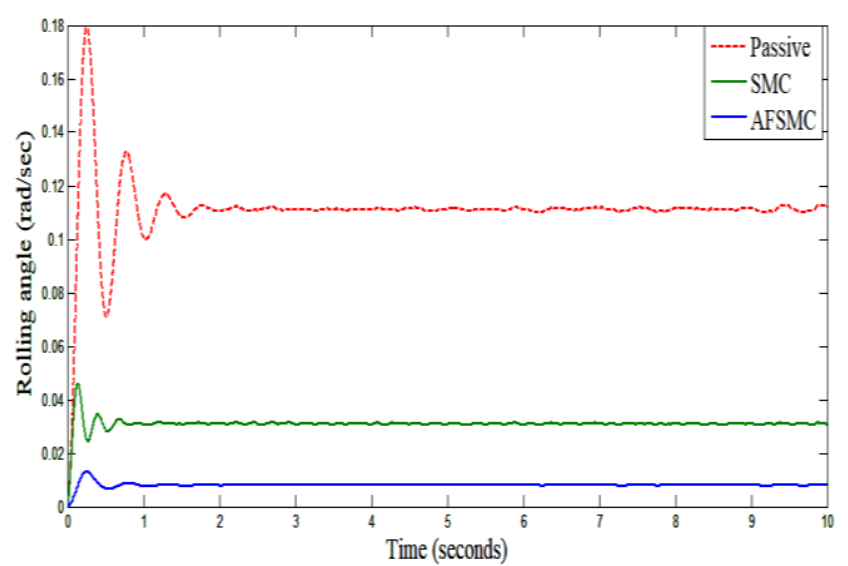

(vi)

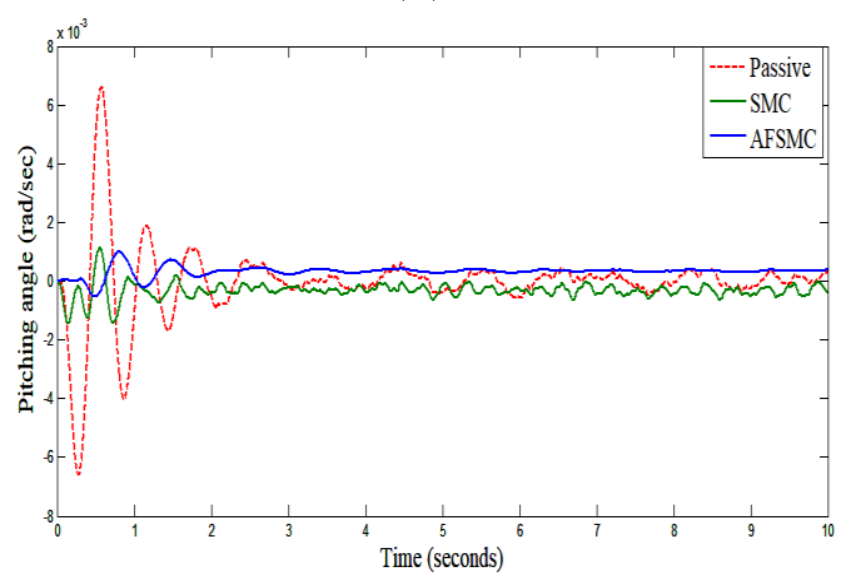

(vii)

Fig. 9: Displacement and rotation of Body (with bending torque) at: (i): $Z_{1}$, (ii): $Z_{2}$, (iii): $Z_{3}$, (iv) $: Z_{4},(\mathrm{v}): Z_{c}$, (vi): $\alpha$, (vii): $\varphi$ 


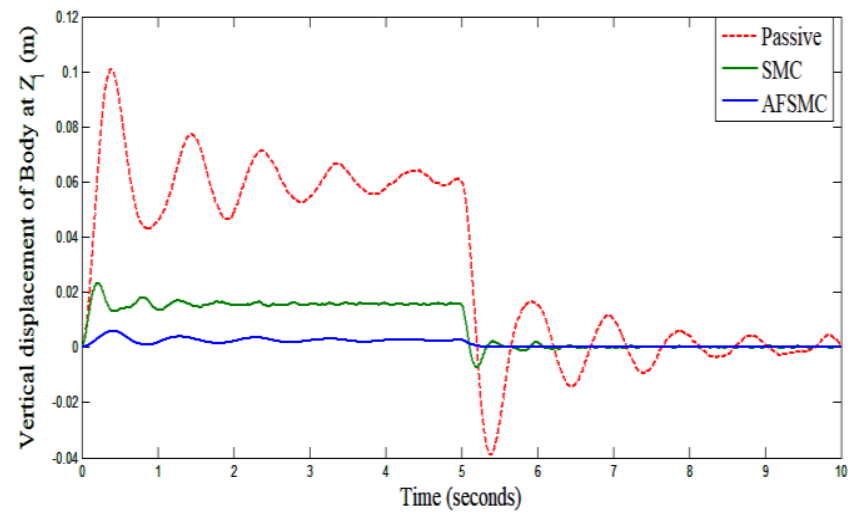

(i)

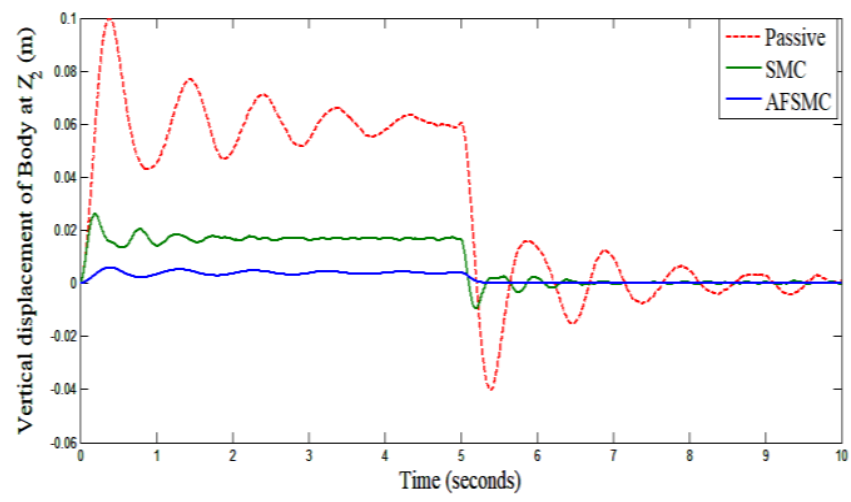

(ii)

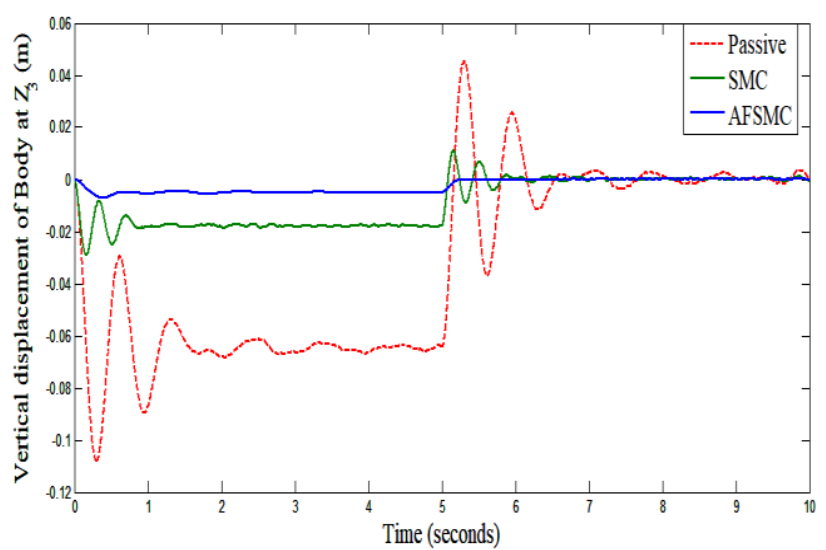

(iii)

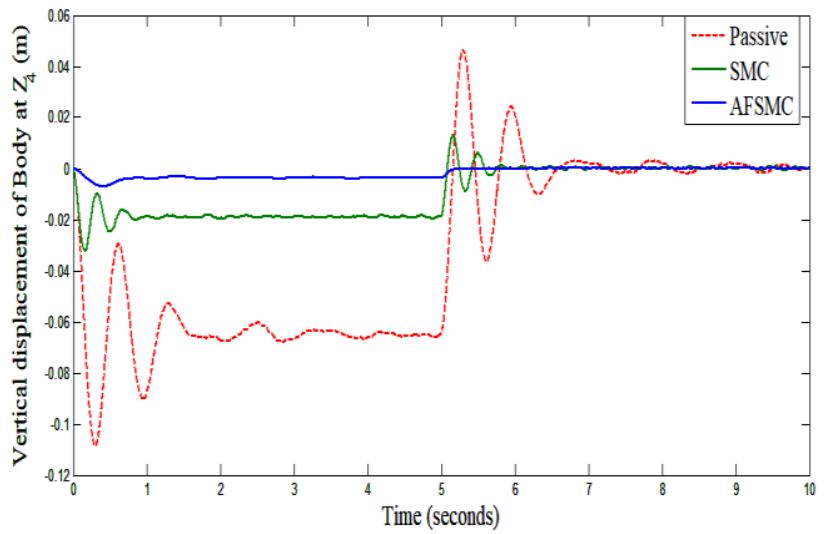

(iv)

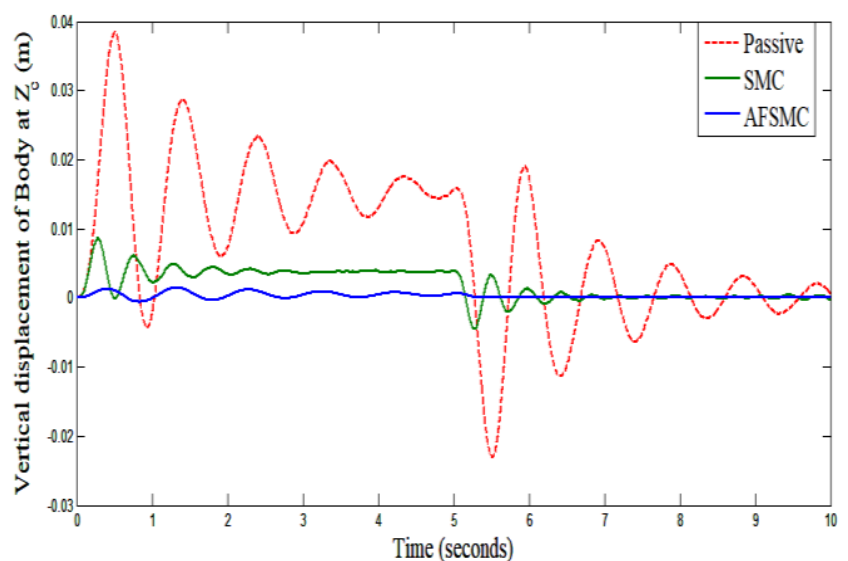

(v)

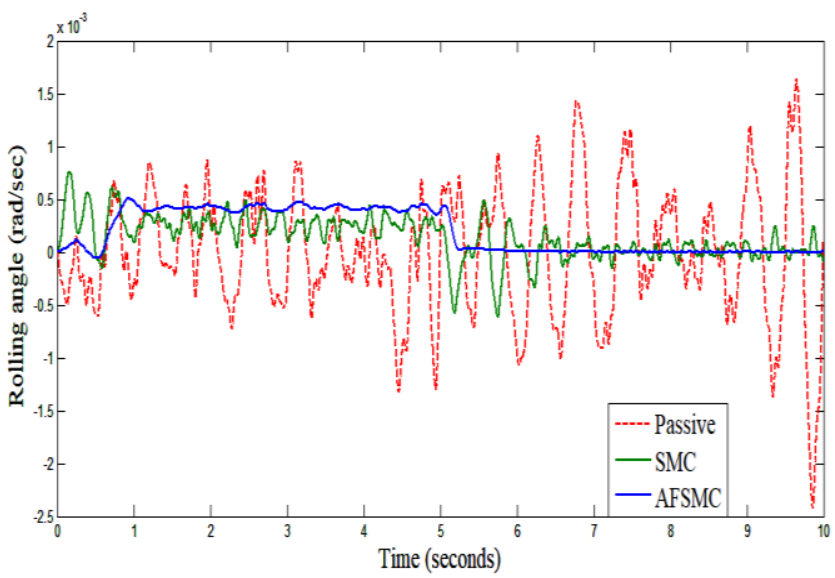

(vi)

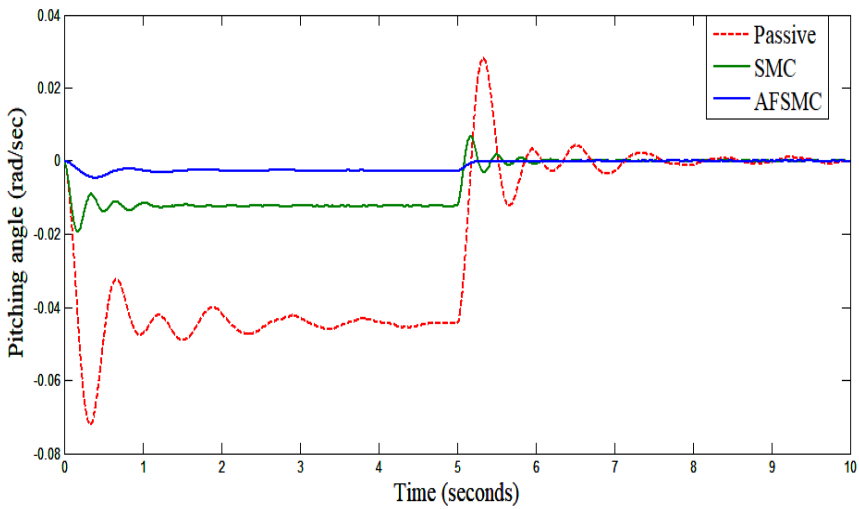

(vii)

Fig. 10: Displacement and rotation of Body (with braking torque) at: (i): $Z_{1}$, (ii): $Z_{2}$, (iii): $Z_{3}$, (iv): $Z_{4}$, (v): $Z_{c},($ vi): $\alpha$, (vii): $\varphi$

\section{ROBUSTNESS TEST}

The performance and the quality of the presented controller is examined through the robustness expression of the proposed controller which is denoted depending on (29). The robustness explains that the proposed controller remains stable under different disturbances input to the system. In this work, the robustness test has been made for the proposed control scheme and compared with the SMC and the passive 
suspension system. The system is presented to random road profile with different amplitudes and fixed frequency. The used amplitudes are $(0.01 \mathrm{~m}$ to $0.07 \mathrm{~m})$, while the frequency is $(0.1 \mathrm{~Hz})$. The cost function is applied as:

$$
\cos t=\sum_{j=1}^{N} \sum_{j=1}^{4}\left(Z_{i j}-Z_{d i j}\right)^{2}
$$

Where, the vertical displacement of each $(j)$ corner in the full active suspension system is $Z_{i j}$ and $Z_{d i j}$ is the desired vertical displacement which is of zero value, so the cost function can be implemented as:

$$
\cos t=\sum_{j=1}^{N} \sum_{j=1}^{4}\left(Z_{i j}\right)^{2}
$$

The outcomes in Table (V), show that the cost function in the proposed controller is acceptable for the random input with different amplitudes.

\section{TABLE V}

THE COST FUNCTION OF PASSIVE, SMC AND AFSMC

\begin{tabular}{|c|c|c|c|}
\hline Amplitude(m) & $\begin{array}{c}\text { Cost }\left(\mathrm{m}^{2}\right) \\
{[\text { Passive] }}\end{array}$ & $\begin{array}{c}\text { Cost }\left(\mathrm{m}^{2}\right) \\
{[\text { SMC] }}\end{array}$ & $\begin{array}{c}\text { Cost }\left(\mathrm{m}^{2}\right) \\
\text { [AFSMC] }\end{array}$ \\
\hline 0.01 & 0.00085 & 0.0011 & $1.875 \mathrm{e}-04$ \\
\hline 0.02 & 0.0394 & 0.0054 & $7.6328 \mathrm{e}-04$ \\
\hline 0.03 & 0.0998 & 0.0128 & 0.00018 \\
\hline 0.04 & 0.1967 & 0.0241 & 0.0039 \\
\hline 0.05 & 0.3462 & 0.0403 & 0.0117 \\
\hline 0.06 & 0.5882 & 0.0631 & 0.0321 \\
\hline 0.07 & 1.0235 & 0.0956 & 0.0816 \\
\hline
\end{tabular}

\section{CONCLUSIONS}

This research study presents and shows the usefulness of using an optimized sliding mode controller with fuzzy estimator for controlling the full vehicle. The proposed control scheme shows good results when compared with sliding mode control strategy and passive system. It is shown that the vertical deflection is minimized in all points of the vehicle. Also, the vertical acceleration in all sides is much minimized. All parameters of the proposed control strategy are optimized with $\mathrm{ABC}$ algorithm. Results show that our proposed control scheme improve the performance under random road profile with and without both (bending and braking) torques. The robustness test of the presented control strategy is also established by applying random road profile with different amplitudes. Simulation results show good robustness properties for the proposed control scheme. Actually, the combination of (AFSMC) and FOPID controller in our developed scheme results is good and high acceptable performance. This control scheme may be implemented using Field Programmable Gate Array (FPGA) and extended for full vehicle suspension system with a passenger seat in future study.

\section{CONFLICT OF INTEREST}

The authors have no conflict of relevant interest to this article.

\section{REFERENCES}

[1] N. S. Bhangal and K. A. Raj, "Fuzzy control of vehicle active suspension system", International Journal of Mechanical Engineering and Robotics Research, vol. 5, no. 2, pp. 144-148, 2016.

[2] W. H. Al-Mutar and T. Y. Abdalla, "Quarter Car Active Suspension System Control Using PID Controller tuned by PSO", Iraqi Journal for Electrical And Electronic Engineering, vol.11, no.2, 2015

[3] D. Wang, D. Zhao, M. Gong and B. Yang, "Nonlinear predictive sliding mode control for active suspension system”, Shock and Vibration, vol. 2018, pp. 1-10, 2018.

[4] F. Beltran-Carbajal, A. Valderrabano-Gonzalez, A. Favela-Contreras, J. L. Hernandez-Avila, I. Lopez-Garcia and R. Tapia-Olvera, "An Active Vehicle Suspension Control Approach with Electromagnetic and Hydraulic Actuators", Actuators, vol. 8, no. 2, pp. 1-18, 2019.

[5] S. D. Nguyen and Q. H. Nguyen, "Design of active suspension controller for train cars based on sliding mode control, uncertainty observer and neuro-fuzzy system", Journal of Vibration and Control, vol. 23, no. 8, pp.1334-1353, 2017.

[6] A. K. Abdulzahra and T. Y. Abdalla, "Fuzzy Sliding Mode Control Scheme for Vehicle Active Suspension System Optimized by ABC Algorithm", International Journal of Intelligent Systems and applications, vol. 11, no.12, pp 1-10, 2019.

[7] S. D. Nguyen and S. B. Choi, "Design of a new adaptive neuro-fuzzy inference system based on a solution for clustering in a data potential field", Fuzzy Sets and Systems, vol. 279, pp.64-86, 2015.

[8] S. D. Nguyen, Q. H. Nguyen, Q. H. and S. B. Choi, "Hybrid clustering based fuzzy structure for vibration control-Part 1: A novel algorithm for building neurofuzzy system", Mechanical Systems and Signal Processing, vol. 50, pp. 510-525, 2015.

[9] A. K. Abdulzahra and T. Y. Abdalla, "Adaptive Fuzzy Super - Twisting Sliding Mode Controller optimized by ABC for Vehicle Suspension System", Basrah Journal for engineering science, vol. 19, no.2, pp. 9-17, 2019.

[10] R. Hosseini, S. D. Qanadli, S. Barman, M. Mazinani, T. Ellis and J. Dehmeshki, "An automatic approach for learning and tuning Gaussian interval type-2 fuzzy membership functions applied to lung CAD classification system", IEEE Transactions on Fuzzy Systems, vol. 20, no. 2, pp. 224-234, 2011.

[11] J. L. Yao, W. K. Shi, J. Q. Zheng and H. P. Zhou, "Development of a sliding mode controller for semi- active vehicle suspensions", Journal of Vibration and Control, vol. 19, no. 8, pp.1152-1160, 2013.

[12] M. Khazaee, A. H. Markazi and E. Omidi, "Adaptive fuzzy predictive sliding control of uncertain nonlinear 
systems with bound-known input delay", ISA transactions, vol. 59, pp.314-324, 2015.

[13] N. Yagiz I. and Yuksek, "Sliding mode control of active suspensions for a full vehicle model", International Journal of Vehicle Design, vol. 26, no. (2-3), pp. 264-276, 2001.

[14]A. Chamseddine, T. Raharijaona and H. Noura, "Sliding mode control applied to active suspension using nonlinear full vehicle and actuator dynamics", In Proceedings of the 45th IEEE Conference on Decision and Control, IEEE, pp. 3597-3602, 2006.

[15] F. Ahmad, K. Hudha and F. Imaduddin, "Modelling, validation and adaptive PID control with pitch moment rejection of active suspension system for reducing unwanted vehicle motion in longitudinal direction", International Journal of Vehicle Systems Modelling and Testing, vol. 5, no. 4, pp. 312-346, 2010.

[16] K. Kayisli and V. Karaman, "Sliding Mode Control of Vehicle Suspension System under Different Road Conditions", International Journal of Engineering Science and Application, vol. 1, no. 2, pp. 72-77, 2017.

[17] A. M. Soliman, M. M. Kaldas, D. C. Barton and P. C. Brooks, "Fuzzy-skyhook control for active suspension systems applied to a full vehicle model", International Journal of Engineering and Technology Innovation, vol. 2, no. 2, pp. 85-96, 2012.

[18] A. K. Abdulzahra and T. Y. Abdalla, "Design of Fuzzy Super Twisting Sliding Mode Control Scheme for Unknown Full Vehicle Active Suspension Systems Using an Artificial Bee Colony Optimization Algorithm", Asian Journal of Control, vol. 23, no. 4, pp. 1966-1981, 2021.

[19] R. Darus and Y. M. Sam, "Modeling and control active suspension system for a full car model", In 2009 5th International Colloquium on Signal Processing \& Its Applications, IEEE, pp. 13-18, 2009.

[20] S. Yun and W. Guangqiang, "Study on optimal control of complete vehicle model with 7 degrees of freedom active suspension", Automobile technology, vol. 6, pp. 1216, 2007.

[21] W. Sun, H. Pan, Y. Zhang and H. Gao, "Multiobjective control for uncertain nonlinear active suspension systems", Mechatronics, vol. 24, no. 4, pp. 318-327, 2014.

[22] R. Guclu, "Fuzzy logic control of seat vibrations of a non-linear full vehicle model", Nonlinear Dynamics, vol. 40, no. 1, pp. 21-34, 2005.

[23]L. Sun and Z. Zheng, "Finite-time sliding mode trajectory tracking control of uncertain mechanical systems", Asian Journal of Control, vol. 19, no. 1, pp. 399-404, 2017.

[24]H. Pan, W. Sun, H. Gao and J. Yu, "Finite-time stabilization for vehicle active suspension systems with hard constraints", IEEE transactions on intelligent transportation systems, vol. 16, no. 5, pp. 2663-2672, 2015.

[25] B. Lin, X. Su and X. Li, "Fuzzy Sliding Mode Control for Active Suspension System with Proportional Differential Sliding Mode Observer", Asian Journal of Control, vol. 21, no. 1, pp. 264-276, 2019.

[26] Y. Sun, J. Xu, H. Qiang and G. Lin, “Adaptive neuralfuzzy robust position control scheme for maglev train systems with experimental verification", IEEE Transactions on Industrial Electronics, vol. 66, no. 11, pp.8589-8599, 2019.

[27] X. Q. Sun, Y. F. Cai, C. C. Yuan, S. H. Wang and L. Chen, "Fuzzy sliding mode control for the vehicle height and leveling adjustment system of an electronic air suspensión", Chinese Journal of Mechanical Engineering, vol. 31, no. 1, p.25, 2018.

[28] S. D. Nguyen, S. B. Choi and Q. H. Nguyen, “A new fuzzy-disturbance observer-enhanced sliding controller for vibration control of a train-car suspension with magneto-rheological dampers", Mechanical Systems and Signal Processing, vol. 105, pp.447-466, 2018.

[29]S. Wen, M. Z. Chen, Z. Zeng, X. Yu, and T. Huang, "Fuzzy control for uncertain vehicle active suspension systems via dynamic sliding-mode approach", IEEE Transactions on Systems, Man, and Cybernetics: Systems, vol. 47, no. 1, pp. 24-32, 2017.

[30] M. A. Khanesar, O. Kaynak, S. Yin and H. Gao, "Adaptive indirect fuzzy sliding mode controller for networked control systems subject to time-varying network-induced time delay", IEEE Transactions on Fuzzy Systems, vol. 23, no. 1, pp.205-214, 2014.

[31]C. P. Cheng, C. H. Chao and T. H. S. Li, "Design of observer-based fuzzy sliding-mode control for an active suspension system with full-car model", In 2010 IEEE International Conference on Systems, Man and Cybernetics, IEEE, pp. 1939-1944, 2010.

[32]S. J. Huang and H. Y. Chen, "Adaptive sliding controller with self-tuning fuzzy compensation for vehicle suspension control", Mechatronics, vol. 16, no. 10, pp. 607-622, 2006.

[33] C. Lauwerys, J. Swevers and P. Sas, "Robust linear control of an active suspension on a quarter car testrig", Control engineering practice, vol. 13, no. 5, pp. 577-586, 2005.

[34]P. Sathishkumar, J. Jancirani, D. John and S. Manikandan, "Mathematical modelling and simulation quarter car vehicle suspension", International Journal of Innovative Research in Science, Engineering and Technology, vol. 3, no. 1, pp. 1280-1283, 2014.

[35]A. A. Aldair, "Neurofuzzy controller based full vehicle nonlinear active suspension systems", Ph.D. dissertation, University of Sussex, 2012. 
[36] T. Y. Abdalla, H. A. Hairik and A. M. Dakhil, "Minimization of torque ripple in DTC of induction motor using fuzzy mode duty cycle controller", 1st International Conference on Energy, Power and Control (EPC-IQ), IEEE, Iraq, pp. 237-244, 2010.

[37]Z. T. Allawi and T. Y. Abdalla, "A PSO-optimized type-2 fuzzy logic controller for navigation of multiple mobile robots", 19th International conference on methods and models in automation and robotics (MMAR), IEEE, pp. 33-39, 2014.

[38] M. I. Hamzah and T. Y. Abdalla, "Mobile Robot Navigation using Fuzzy Logic and Wavelet Network", International Journal of Robotics and Automation (IJRA), vol. 3, no. 3, pp. 191-200, 2014.

[39] W. H. Al-Mutar and T. Y. Abdalla, "Quarter car active suspension system control using fuzzy controller tuned by pso", International Journal of Computer Applications, vol. 127, no. 2, pp. 38-43, 2015.

[40]T. Y. Abdalla and A. A. Abdulkareem, "PSO optimized fuzzy control scheme for mobile robot path tracking”, International Journal of Computer Applications, vol. 76, no. 2, pp. 11-17, 2013.

[41]Z. T. Allawi and T. Y. Abdalla, "An optimal defuzzification method for interval type-2 fuzzy logic control scheme", Science and Information Conference (SAI), IEEE, pp. 619-627, 2015.

[42] J. Liu, "Sliding Mode Control Using MATLAB", Academic Press, 2017.

[43] S. Gad, H. Metered, A. Bassuiny and A. M. Abdel Ghany, "Multi-objective genetic algorithm fractionalorder PID controller for semi-active magnetorheologically damped seat suspension", Journal of Vibration and Control, vol. 23, no. 8, pp.1248-1266, 2017.

[44] M. Zamani, M. Karimi-Ghartemani and N. Sadati, "FOPID controller design for robust performance using particle swarm optimization", Fractional Calculus and Applied Analysis, vol. 10, no. 2, pp.169-187, 2007.

[45]Z. Bingul and O. Karahan, "Comparison of PID and FOPID controllers tuned by PSO and ABC algorithms for unstable and integrating systems with time delay", Optimal Control Applications and Methods, vol. 39, no. 4, pp.1431-1450, 2018.

[46] T. Y. Abdalla, “Adaptive Fuzzy FOPID Control Scheme for Path tracking of Mobile Robot", International Journal of Computer Applications, vol.181, no.22, pp.1-5, 2018.

[47]D. Karaboga, "An idea based on honey bee swarm for numerical optimization", Technical report-tr06, Erciyes university, engineering faculty, computer, vol. 200, pp. 1-10, 2005.

[48] W. Liao, Y. Hu and H. Wang, “Optimization of PID control for DC motor based on artificial bee colony algorithm", In Proceedings of the 2014 International Conference on Advanced Mechatronic Systems, IEEE, pp. 23-27, 2014.

[49]A. A. Aldair, E. B. Alsaedee and T. Y. Abdalla, "Design of ABCF Control Scheme for Full Vehicle Nonlinear Active Suspension System with Passenger Seat", Iranian Journal of Science and Technology, Transactions of Electrical Engineering, vol. 43, no. 1, pp. 289-302, 2019.

[50] G. Yan and C. Li, "An effective refinement artificial bee colony optimization algorithm based on chaotic search and application for pid control tuning", Journal of Computational Information Systems, vol. 7, no. 9, pp. 3309-3316, 2011.

[51] B. H. Adebiyi, M. B. Mu'azu, A. M. S. Tekanyi, A. T. Salawudeen and R. F. Adebiyi, "Knowledge-Based Artificial Bee Colony Algorithm for Optimization Problems", Journal of Engineering Research, vol. 22, pp. 1-13, 2017. 